\title{
Recall, Recognition and Priming Characteristics of Middle School Students with Depressive Symptoms
}

\author{
Yu Guang1, Dajun Zhang2, Zhengzhi Feng1 ${ }^{*}$ \\ ${ }^{1}$ Department of Psychology, Third Military Medical University, Chongqing, China \\ ${ }^{2}$ Department of Psychology, Southwest University, Chongqing, China \\ Email: ${ }^{*}$ fzz@tmmu.edu.cn
}

Received 20 August 2015; accepted 25 October 2015; published 28 October 2015

Copyright (C) 2015 by authors and Scientific Research Publishing Inc.

This work is licensed under the Creative Commons Attribution International License (CC BY). http://creativecommons.org/licenses/by/4.0/

(c) (i) 0pen Access

\begin{abstract}
A Tversky's experiment paradigm was used to explore the social cognitive processing of middle school students with depressive symptoms. The results showed 1) there was no significant difference in the recall of social information processing between experimental and control group; 2 ) the recognition of social information processing related to the level of processing; 3 ) the negative priming of social information processing was caused by negative biases of processing of negative items and the neutral items. These findings reveal that there would be negative biases of recall, recognition and priming in middle school students with depressive symptoms.
\end{abstract}

\section{Keywords}

Middle School Students, Depressive Symptoms, Social Information Processing, Processing Biases

\section{Introduction}

According to Beck's cognitive theory of depression, depression is caused by negative cognitive schemata that influence the encoding, storing and retrieving of information. A series of empirical studies about cognitive processes have provided supporting evidence for this theory. For example, Derry \& Kuiper's (1981) presented participants with the depressive and nondepressed adjectives on the 7-point scale and required them to rate to what degree the adjectives were suitable to describe themselves, then gave them a free recall test. They found that clinical depressives recalled depressed-content, self-referenced adjectives but normal and nondepressed psychiatric controls did not. Lately, Dobson \& Shaw (1987) changed the rating of the adjectives into "Yes” and

${ }^{*}$ Corresponding author. 
"No" judgments and called the experimental paradigm as self-related encoding task to detect the contents of self schemata. Watkins et al. (1992) used "stem supplement" and Denny et al. (1992) employed "incomplete phrase supplement and report of inner-hidden test of memory" to investigate these cognitive processes, etc. These researchers discovered positive self schemata of the nondepressed, positive-negative balanced self schemata of the mildly depressed and negative self schemata of clinical depressives. These results indicate that with the aggravation of depression, self schemata experience a transition process from positive to negative. In addition, some studies found that negative self schemata disappeared with the remission of depressive symptoms either under natural depressive states or under experiment-induced depressive states. Therefore, depressogenic self schemata is not a stable structure and related to emotional states, which was inconsistent with Beck's theory.

Abramson et al. (1989) proposed a theory of social cognition positing that the development of depression is closely related to social and cognitive psychological factors. Based on this theory, some researchers tried to find out the social and cognitive proneness causing depression (Chen \& Qian, 1998; Chen \& Zheng, 1999; Garber, Weiss, \& Shanley, 1993; Bandura \& Pastorelli, 1999; Kessler, 1997; Chen et al., 2001). These studies found that depression was not simply an emotional disorder or a cognitive handicap, but accompanied with mental and behavioral problems such as deficits of sociality development. However, their studies have not demonstrated several core issues. Firstly, what is the essence of negative cognitive schemata and how to process the information on life events? Secondly, how do social factors function and what is the core mechanism of bad sociality of depressed individuals?

Many Studies on children's aggressive behavior and learning disability have provided beneficial enlightenment. Researchers applied information processing theory to studies about social behavior, and explored the processing mechanism of social cognition of children's aggressive behavior and learning disability, which had further developed the theory in relevant research fields (Dodge \& Price, 1994; Egan \& Monson, 1998). Simultaneously, studies on basic cognitive process of emotional disorder have penetrated deeply to the aspect of information processing bias, mainly laying emphasis on perceptual encoding, comprehension of problems and memory storage (Wang \& Fu, 2001). These researches have provided a new angle of view for studies on depression. Therefore, the goal of the current study was to explore the processing pattern of social information in adolescents with depressive symptoms by integrating social cognition and information processing to provide theoretical support for the mechanism of adolescent depression.

We designed a series of experiments based on Tversky's experimental paradigm of social cognition (Tversky \& Marsh, 2000). Tversky \& Marsh (2000) used a participant-related story (e.g. a story of two roommates) and controlled the types of sentence items (positive, negative and neutral), the number of sentence items (18 sentences in each item type) and the conditions of recall and recognition (positive, negative and neutral) of the participants, and then analyzed the types and number of sentence items recalled and recognized by participants under different conditions, which revealed that distorted rehearsal of life events could cause distorted memory. The purpose of the paradigm was to test these cognitive processes about life events. In our study, we added 1) a group of middle school students with depressive symptoms, 2) the link of priming information processing, and 3) the analyses of bias of recall, recognition and priming, with the purpose of studying the processing mode for social information in the middle school students with depressive symptoms.

\section{Experiment 1: Recall Characteristics of Middle School Students with Depressive Symptoms under Different Conditions}

\subsection{Participants and Recruitment}

Depression group. The participants in depression group met all the following criteria: 1) meeting the diagnostic criteria of depressive symptoms of Beck's Depression Inventory (Beck et al., 1979) and Zung's Rating Scale for Depression (William \& Zung, 1965); 2) aged 11 - 19 years and not in menstrual period for the females; 3) without severe physical disease or other mental disorders; 4) without immunoregulant or hormone preparation within at least six months; 5) taking no psychotropic drug or antipyretic analgesic within at least two weeks; 6) without acute or chronic infection, trauma, inflammation, fever or hypersensitiveness in last two weeks; and 7) having no history of alcohol or drug abuse. Forty-nine middle school students (23 males and 26 females, aged $15 \pm 3$ ) with depressive symptoms took part in this study. They were recruited from 6538 middle school students ranging from the first grade in junior middle schools to the third grade in senior middle schools in Chongqing Municipality and Sichuan Province in China. These participants and their parents signed consent forms for agreeing 
to participate in the study.

Nondepression group. The participants were forty-nine healthy middle school students ( 25 males and 24 females, aged $15 \pm 3$ ) from the same schools of participants in depression group. Except having no history or family history of mental disorder, other selection criteria for were the same as the depression group.

\subsection{Study Design}

We used the mixed design of 2 (group types: depression and nondepression) $\times 3$ (sentence types: positive, negative and neutral) $\times 3$ (recall conditions: positive, negative and neutral) in this study, among which group type was a between-group factor, and sentence types and recall conditions were within-group factors.

\subsection{Materials}

Beck Depression Inventory (BDI). The self-report inventory including 21 items is used to assess the severity of depressive symptoms and each item is rated on a four-point scale ranging from 0 to 3 ( $0=$ never or occasionally; 1 = mild; 2 = moderate; 3 = severe) (Beck et al., 1961). The 21 items cover major features of depression including sadness, pessimism, a sense of failure, dissatisfaction, guilt, punishment, self-dislike, self-accusations, suicidal ideas, crying, irritability, social withdrawal, indecisiveness, body image change, work difficulty, insomnia, fatigability, loss of appetite, weight loss, somatic preoccupation and loss of libido. The total BDI score is the sum of all items. BDI scores below 4, ranged 5 - 13, ranged 14 - 20, and over 21 indicate no or extremely mild, mild, moderate, or severe depressive symptoms respectively.

Zung Rating Scale for Depression (SDS). It is a 20 item self-rating scale with a four-point scale ranging from 1 to 4 ( 1 = never or occasionally; 2 = sometimes; 3 = often; 4 = almost all of the time) (William \&Zung, 1965). There six somatic items, six cognitive items, four behavioral items, three affective items, and one social relation item. Half of them are worded positively and half negatively. These items reflect four specific symptoms of depression: mental-affective symptoms, somatization disorder, psychomotor disorder and psychological disorder for depression. The total score is the sum of all items. SDS scores below 40, ranged 41 - 47, ranged 48 55, and over 56 indicate no, mild, moderate, or severe depressive symptoms respectively.

Reading material "The Roommate Story". The story addressed the participant as "you" and described the first week at school with two new roommates. After a brief introduction, the story described a typical living scene of middle school students. In total, the two roommates have 54 behaviors and activities. The behaviors and activities of each roommate were described with different sentence items, which included 9 positive (active, communicative and vivid), 9 negative (worried, disordered and nonchalant) and 9 neutral items (neutral, descriptive and objective) (Tversky \& Marsh, 2000; see Appendix A).

We established the reliability and validity of the items in preliminary experiment. Using Tversky's experimental reading material (Tversky \& Marsh, 2000), 50 junior middle school students, 50 senior middle school students, and 15 postgraduates encoded the sentence items according to the definitions of positive, negative and neutral sentence items made by Tversky. The internal coherence coefficient (homogeneity reliability) and the stability coefficient (re-test reliability) were taken as reliability indexes, and structure validity was considered as validity index (see Table 1 and Table 2).

The results showed that the related coefficients between the positive, negative and neutral sentence items of the reading material and the corresponding belonged types are $0.7427-1.000$ and the related coefficients between the positive, negative and neutral sentence items are $0.000-0.3273$, indicating that all the sentence items accorded with the demands of psychometrics. Furthermore, in order to further verify the validity of the reading material, we took Tversky's experimental material as the validity criterion and added up the sentence items

Table 1. Reliability and validity coefficients of items in "The Roommate Story".

\begin{tabular}{ccccc}
\hline Item types & Cronbach $\alpha$ & Re-test & $\mathrm{r}_{1}$ & $\mathrm{r}_{2}$ \\
\hline Positive & 0.8744 & 0.9123 & $0.7518-1.000$ & $0.000-0.2071$ \\
Negative & 0.8631 & 0.8718 & $0.7445-1.000$ & $0.000-0.3273$ \\
Neutral & 0.8401 & 0.8635 & $0.7427-1.000$ & $0.000-0.3144$ \\
\hline
\end{tabular}

Notes. $\mathrm{r}_{1}$ : coefficient correlation between items and their types. $\mathrm{r}_{2}$ : coefficient correlation between items and other types. 
Table 2. Frequency percentages of items in "The Roommate Story".

\begin{tabular}{cccc}
\hline $\begin{array}{c}\text { Item types } \\
\text { (number of items) }\end{array}$ & $\begin{array}{c}\text { Junior middle school students } \\
(\mathrm{n}=50)\end{array}$ & $\begin{array}{c}\text { Senior middle school students } \\
(\mathrm{n}=50)\end{array}$ & $\begin{array}{c}\text { Postgraduates } \\
(\mathrm{n}=15)\end{array}$ \\
\hline Positive (18) & $69.35 \%-100 \%$ & $71.23 \%-100 \%$ & $75.40 \%-100 \%$ \\
Negative (18) & $62.34 \%-100 \%$ & $62.56 \%-100 \%$ & $71.39 \%-100 \%$ \\
Neutral (18) & $63.78 \%-100 \%$ & $64.68 \%-100 \%$ & $72.48 \%-100 \%$ \\
\hline
\end{tabular}

chosen by junior middle school students, senior middle school students and postgraduates respectively, and then calculated the frequencies. We found that the frequencies were consistent with Tversky's definition (Tversky \& Marsh, 2000).

Testing material for recall. We prepared three instructions for inducing recall of positive, negative, and neutral condition respectively (see Appendix B).

\subsection{Procedure}

Every five participants were tested each time. There were two experimental phases: study phase and recall-test phase.

Study phase. In this phase, each participant was given a copy of "The Roommate Story", and the experimenter read the following directions to him/her: "Please read the story carefully. Five minutes later, you will be required to recall the details of the story."

Recall-test phase. After reading the story, participants performed a task of continuous inverse calculation of "50-3" for three minutes. Then they had a recall test under the positive condition (see the introduction I in Appendix B). Ten minutes later, they completed another continuous calculation of " $500+3$ " for three minutes. Then they had a recall test under the negative condition (see the introduction II in Appendix B). After that, the participants implemented continuous calculation of " $2+2$ " for three minutes. Next, they had a recall test under neutral conditions (see the instruction III in Appendix B).

\subsection{Statistical Analysis}

Two trained postgraduates majoring in psychology assessed the recalled material of the participants as positive, negative, and neutral types. The assessing criteria were to judge and calculate the activities or descriptive sentences in the recalled material of the participants identical to the positive, negative, and neutral items in the reading material. Then the recalled volume was analyzed with ANOVA and Student's $t$ test between groups.

\subsection{Results}

2.6.1. Effects of Positive Conditions on Recall of Middle School Students with Depressive Symptoms Guided by the positive instruction of recall, a significant main effect of sentence item type (positive, negative and neutral) was found, indicating that the participants with or without depressive symptoms recalled more positive items, $F(2,77)=149.090, p<0.01$. We also found a significant interaction between the group type (depression and nondepression) and sentence item type, $F(2,77)=3.888, p<0.05$, indicating a difference in recalled volume of positive items between depression group and nondepression group, $t=2.405, p<0.05$ (see Figure 1).

\subsubsection{Effects of Negative Conditions on Recall of Middle School Students with Depressive Symptoms}

Guided by the negative instruction of recall, a significant main effect of sentence item showed that the participants with depressive symptoms recalled more negative items, $F(2,84)=392.582, p<0.01$. We also found a significant main effect of group type, which indicates a difference in recalled volume of items between depression group and nondepression group, $F(1,84)=167.888, p<0.01$. Meanwhile, a significant interaction was found between group type and sentence item type, $F(2,84)=3.888, p<0.05$. There was no significant difference in the volume of recalled positive items between the depression group and the nondepression group. But in the depression group, the total recalled items, recalled negative items and recalled neutral items were significantly more than those of the nondepression group, $t=4.708, p<0.01, t=3.518, p<0.01, t=2.976, p<0.01$ (see Figure 2). 


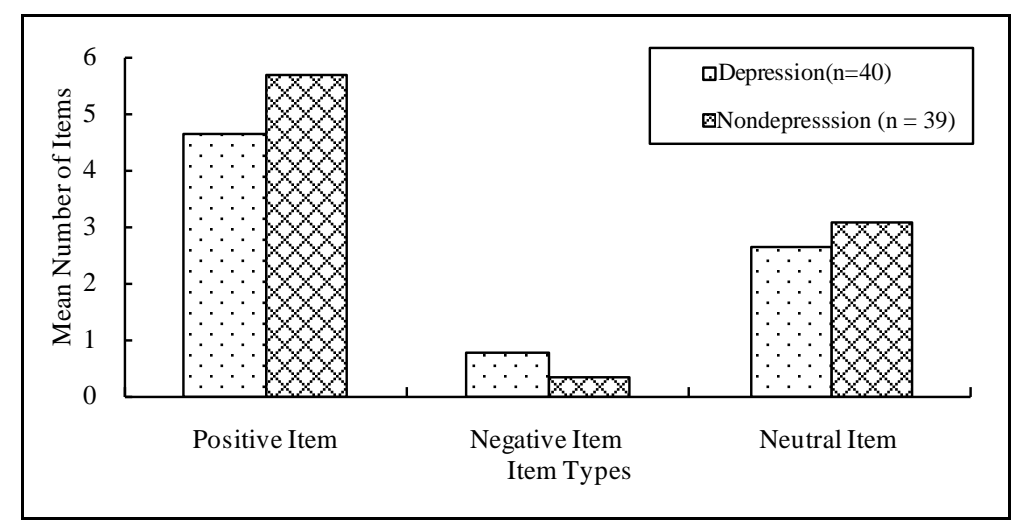

Figure 1. Effect of positive conditions on recall of participants.

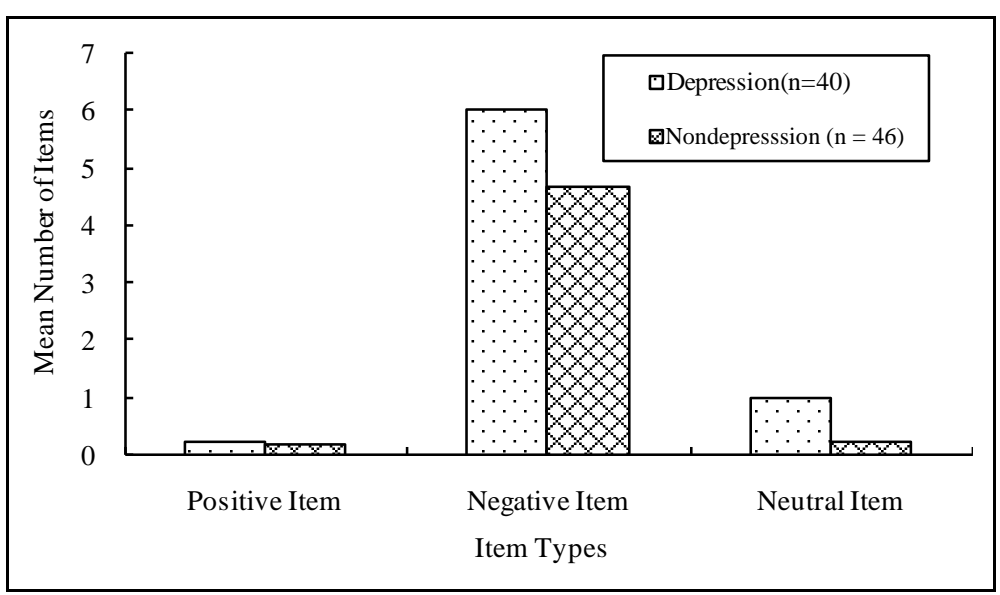

Figure 2. Effect of negative conditions on recall of participants.

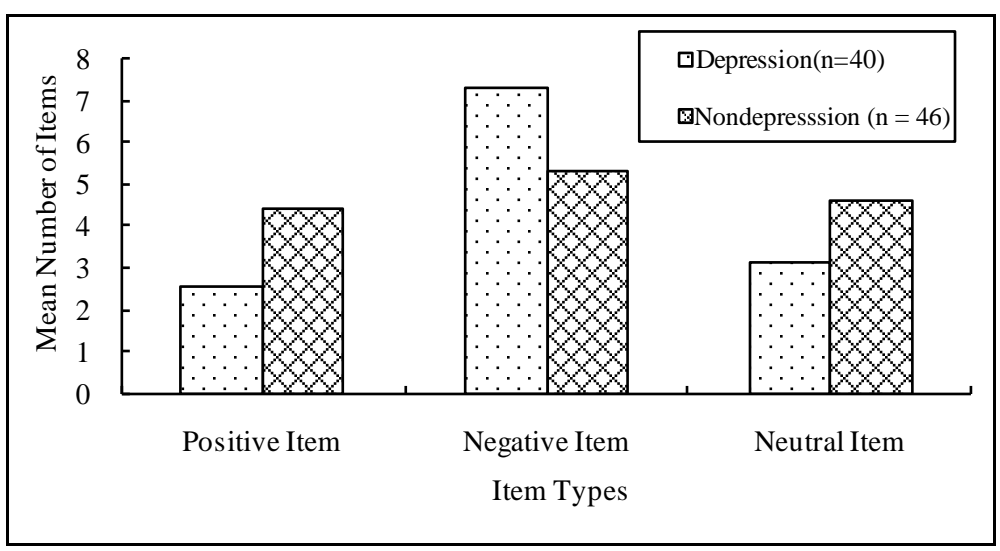

Figure 3. Effect of neutral conditions on recall of participants.

2.6.3. Effect of Neutral Conditions on Recall of Middle School Students with Depressive Symptoms Guided by the negative instruction of recall, a significant main effect of sentence item type was found, $F(2,84)$ $=36.165, p<0.01$. And a significant interaction was found between group type and sentence item type, $F(2,84)$ $=17.307, p<0.01$. Under neutral conditions the recalled positive items and neutral items in the depression group were significantly less than those of the nondepression group, $t=4.307, p<0.01, t=2.270, p<0.05$, while the recalled negative items, $t=3.817, p<0.01$, were significantly more than those of the nondepression group (see Figure 3). 


\subsubsection{Effect of Different Recall Conditions on Recall Bias of Middle School Students with Depressive Symptoms}

To further analyze the recall bias of the middle school students with depressive symptoms, the positive recall bias was calculated according to the formula: positive recall bias = recalled positive items - recalled negative items. The results of the two groups were shown in Figure 4.

Through analyzing the recalled positive, negative, and neutral items of the participants under different conditions with ANOVA of 2 (depression and nondepression) $\times 3$ (positive, negative, and neutral sentence items), a significant main effect of sentence item was found, $F(2,77)=384.778, p<0.01$. A significant main effect of group was also found, $F(1,77)=49.424, p<0.01$. And a significant interaction was found between group type and sentence item type, $F(2,77)=7.296, p<0.01$. Figure 4 shows that under positive conditions, the positive recall bias of nondepression group was significantly greater than that of the depression group, $t=3.114, p<0.01$. But under negative and neutral conditions, the negative recall bias of depression group was greater than that of the nondepression group, $t=3.269, p<0.01, t=5.903, p<0.01$.

\section{Experiment 2: Recognition Characteristics of Middle School Students with Depressive Symptoms}

\subsection{Participants and Recruitment}

Participants were from the same schools as participants in Experiment 1. They were divided into depression group (39 participants) and nondepression group (40 participants) with the same selection criteria and sampling methods as Experiment 1.

\subsection{Design}

We used the mixing variance design of 2 (groups: depression and nondepression) $\times 3$ (sentence types: positive, negative and neutral) in this study, among which, the variance between the participants was the depressive level, and the variance within the participants was the sentence types.

\subsection{Materials}

Reading material “The Roommate Story” We used the same material as Experiment 1 (see Appendix A).

Testing material for recognition. The materials (see Appendix C) consisted of 108 sentences about the roommate in the story. Fifty-four sentences were from the reading material (the activity or behavior of each roommate being described by 9 positive, negative and 9 neutral sentences respectively). And the other 54 sentences were descriptions of the two roommates (each roommate being also described by 9 positive, 9 negative and 9 neutral sentences respectively), which were not in the reading material but matched with the sentences in the reading material.

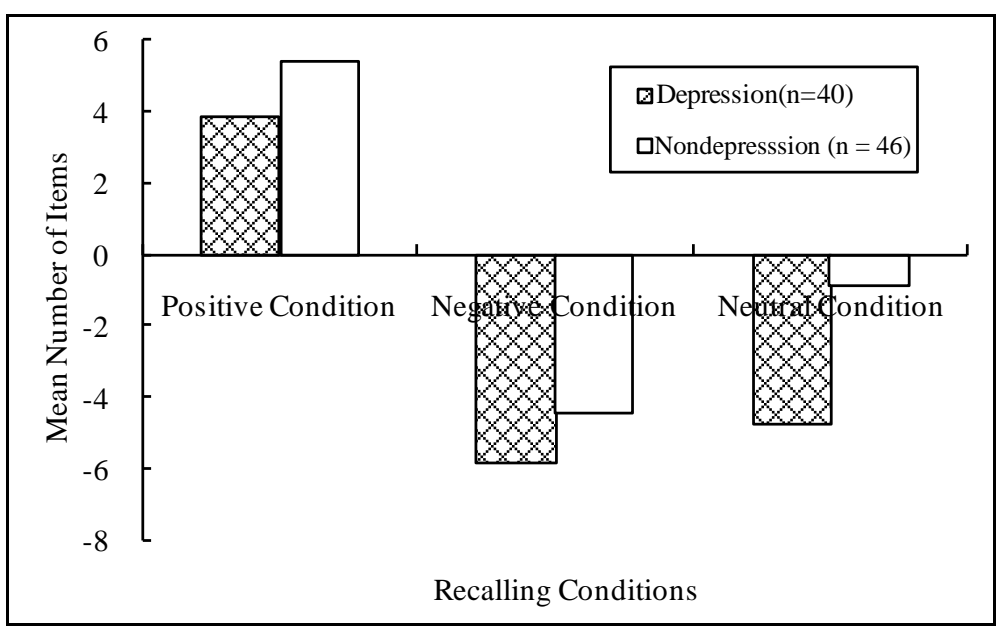

Figure 4. Effect of different recall conditions on recall bias of participants. 


\subsection{Procedure}

Every five participants were tested each time. There were two phases of the experiment: study phase and recognition-test phase.

Study phase. The study phase was the same as Experiment 1.

Recognition-test phase. After five minutes of reading, the participants performed continuous calculation of “500-3” for three minutes. Then the participants had a recognition test (see Appendix C) for 10 minutes.

\subsection{Results}

\subsubsection{Analysis on Recognized Volume of Positive, Negative and Neutral Items by Middle School Students with Depressive Symptoms}

Recognized volume referred to the sentence number that the participants recognized correctly among the 108 sentences, which included 54 key sentences occurring in the reading materials (original items) and 54 sentences matched with the original ones (newly-added items).

An interaction relationship was found between group type and sentence item type, $F(2,70)=17.922, p<$ 0.01 . For the newly-added items, significant main effects of sentence item and group type were found, $F(2,70)$ $=10.503, p<0.01, F(2,70)=5.556, p<0.05$. Table 3 shows that depression group recognized significantly more original negative items but fewer positive items than nondepression group, $t=3.560, p<0.01, t=4.208, p$ $<0.01$. However, for the newly-added items, only negative items had significant group difference, $t=2.559, p<$ 0.05. Therefore, depressed participants recognized more negative items whether they were original or newly-added.

\subsubsection{Analysis on Recognition Bias of Middle School Students with Depressive Symptoms}

Recognition bias referred to the difference between recognized volume of positive and negative items. It was generally expressed as positive recognition bias (positive recognition bias = recognized positive items - recognized negative items). Figure 5 shows that the depressed participants had negative recognition bias for both the original and newly-added items, while nondepressed participants had positive recognition bias for the original items but negative bias for the newly-added items.

Through analyzing the recognition bias with ANOVA of 2 (group type: depression and nondepression) $\times 2$ (recognition bias type: for original items and for newly-added items), no significant main effect of group type was found. But there was a significant main effect of recognition bias type, $F(1,70)=28.484, p<0.01$. Meanwhile, an interaction was found between groups and the newly-added and original items, $F(1,70)=15.820, p<$ 0.01 . We also found that for the original items depressed participants had significantly larger recognition bias than nondepressed participants did, $t=5.848, p<0.01$.

\section{Experiment 3: Priming Characteristics of Middle School Students with Depressive Symptoms}

\subsection{Participants and Recruitment}

Participants were from the same schools as participants in Experiment 1. They were divided into depression group (30 participants) and nondepression group (32 participants) with the same selection criteria and sampling methods as that in Experiment 1.

Table 3. Recognized volume of positive, negative and neutral items of participants.

\begin{tabular}{ccccccc}
\hline Groups & \multicolumn{2}{c}{ Positive items } & \multicolumn{2}{c}{ Negative items } & \multicolumn{2}{c}{ Neutral items } \\
\hline & Original & Newly-added & Original & Newly-added & Original & Newly-added \\
Depression $(\mathrm{n}=36)$ & $13.61 \pm 1.81$ & $16.27 \pm 1.41$ & $15.47 \pm 2.09$ & $17.11 \pm 1.30$ & $14.86 \pm 2.91$ & $15.78 \pm 1.74$ \\
Nondepression $(\mathrm{n}=36)$ & $15.11 \pm 1.14$ & $15.89 \pm 1.16$ & $13.53 \pm 2.52$ & $16.14 \pm 1.86$ & $14.75 \pm 1.29$ & $15.33 \pm 1.82$ \\
$t$ & 4.208 & 1.277 & 3.560 & 2.559 & 0.209 & 1.058 \\
$p$ & $<0.01$ & $>0.05$ & $<0.01$ & $<0.05$ & $>0.05$ & $>0.05$ \\
\hline
\end{tabular}




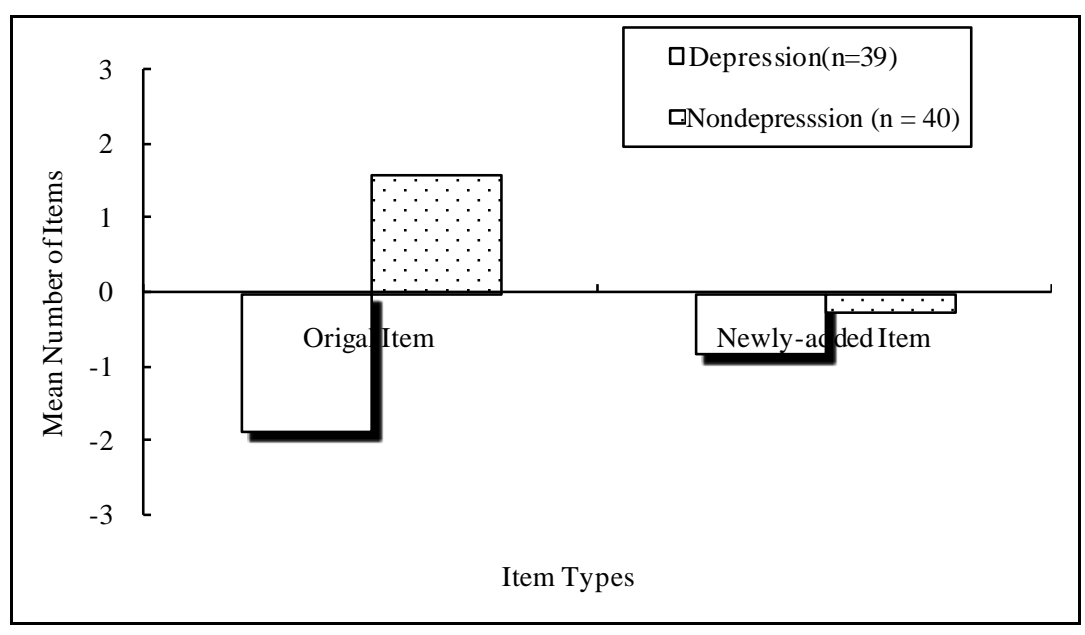

Figure 5. Analysis on recognition bias of participants.

\subsection{Design}

We used the mixing variance design of 2 (group type: depression group and nondepression group $\times 3$ (sentence item type: positive, negative, and neutral items) in this study.

\subsection{Materials}

Reading material “The Roommate Story”. We used the same material as Experiment 1 (see Appendix A).

Testing material for priming. We used a list of positive, negative and neutral key sentences in the reading material were taken as priming stimulus (see Appendix D). The priming stimulus consisted of 54 sentences (including 18 positive, 18 negative and 18 neutral sentences), which includes activities or descriptions of the two roommates in the reading material. The structure of sentence in this test were as "Liu Xing is talking loudly with his next-desk neighbor, and he will...”.

\subsection{Procedure}

Every five participants were tested each time. There were two experimental phases: study phase and priming-test phase.

Study phase. The study phase was the same as that of Experiment 1.

Priming-test phase. After five minutes of reading, the participants performed an unrelated talk of continuous calculation of " $500-3$ " for three minutes. Then the participants had a priming test for 20 minutes (the instructions are shown in Appendix D).

\subsection{Results}

\subsubsection{Analysis on Priming Effect of Middle School Students with Depressive Symptoms}

A significant main effect of item type was found, $F(2,60)=4.587, p<0.05$. And an interaction was found between the group type and the item type, $F(2,60)=5.770, p<0.01$, which mainly shows that the primed negative items in the depression group were significantly more than those of the nondepression group, $t=2.944, p<$ 0.01 (see Figure 6).

\subsubsection{Analysis on Priming Processing of Positive, Negative and Neutral Items by Middle School Students with Depressive Symptoms}

Through analyzing the primed volume of the positive, negative, and neutral items of the participants under negative conditions with ANOVA of 2 (group type: depression and nondepression) $\times 3$ (primed item type: positive, negative and neutral), a significant main effect of the primed item type was found, $F(2,60)=98.464, p<0.01$, and a significant interaction was found between group type and primed item type under negative conditions, $F$ $(2,60)=72.807, p<0.05$. A significant main effect was also found in the priming processing under positive 
conditions, $F(2,60)=72.807, p<0.01$. Furthermore, we found a significant main effect of priming processing under neutral conditions, $F(2,60)=50.765, p<0.01$, and a significant interaction was found with the groups, $F$ $(2,60)=6.041, p<0.01$. Further analysis found that the middle school students with depressive symptoms primed by negative and neutral items produced significantly more negative items and significantly less neutral items than those without depressive symptoms (see Table 4 and Figure 7).

\subsubsection{Analysis on Priming Bias of Middle School Students with Depressive Symptoms}

The positive priming bias was calculated according to the formula: positive priming bias = primed positive items - primed negative items. The results are shown in Figure 8.

Through analyzing the priming bias of the positive, negative, and neutral items of the participants with ANOVA of 2 (depression and nondepression) $\times 3$ (positive, negative and neutral sentence items), significant main effects of primed item type and group was found, $F(2,60)=346.436, p<0.01, F(1,60)=7.921, p<0.01$. We further found that primed by the total items, negative items and neutral items, depression group generated significantly more negative items compared with the nondepression group, $\mathrm{t}=2.814, p<0.01, \mathrm{t}=2.556, p<$ 0.05 and $\mathrm{t}=2.581, p<0.05$.

\subsection{Discussion}

\subsubsection{Recall Characteristics of Middle School Students with Depressive Symptoms under Different Conditions}

By comparing the recalled positive, negative and neutral items under different recall conditions between depression

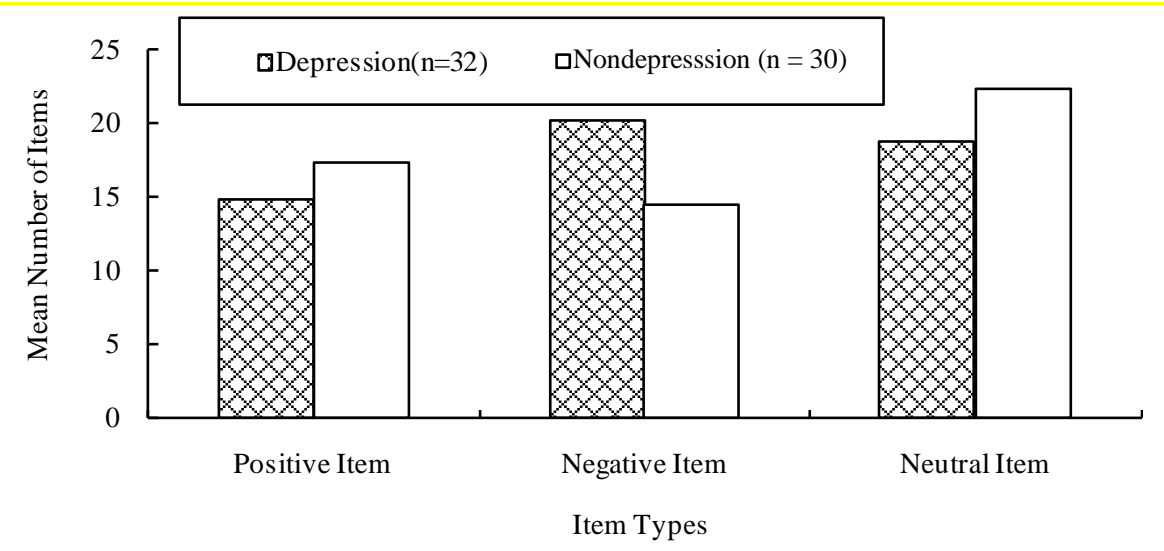

Figure 6. Analysis on priming effect of participants.

Table 4. Analysis on priming processing of positive, negative and neutral items of participants.

\begin{tabular}{cccccc}
\hline \multirow{2}{*}{ Priming item types } & Produced item types & Depression group $(\mathrm{n}=32, \%)$ & Nondepression group $(\mathrm{n}=30, \%)$ & $\mathrm{T}$ & $p$ \\
\hline \multirow{2}{*}{ Negative } & Negative & $12.34(4.30)$ & $9.90(3.51)$ & 2.440 & $<0.05$ \\
& Positive & $1.18(1.14)$ & $1.90(1.71)$ & 1.938 & $>0.05$ \\
& Neutral & $4.46(3.93)$ & $6.20(2.74)$ & $1.996 \quad=0.05$ \\
\multirow{2}{*}{ Positive } & Negative & $2.81(2.46)$ & $1.83(2.22)$ & $1.635 \quad>0.05$ \\
& Positive & $9.62(3.13)$ & $10.63(3.69)$ & 1.161 & $>0.05$ \\
& Neutral & $5.56(2.87)$ & $5.60(3.11)$ & $0.049>0.05$ \\
\multirow{2}{*}{ Neutral } & Negative & $5.18(3.42)$ & $2.80(2.49)$ & $3.121<0.01$ \\
& Positive & $4.09(2.41)$ & $4.80(2.68)$ & $1.091 \quad>0.05$ \\
& Neutral & $8.75(2.77)$ & $10.53(3.10)$ & $2.389<0.05$ \\
\hline
\end{tabular}



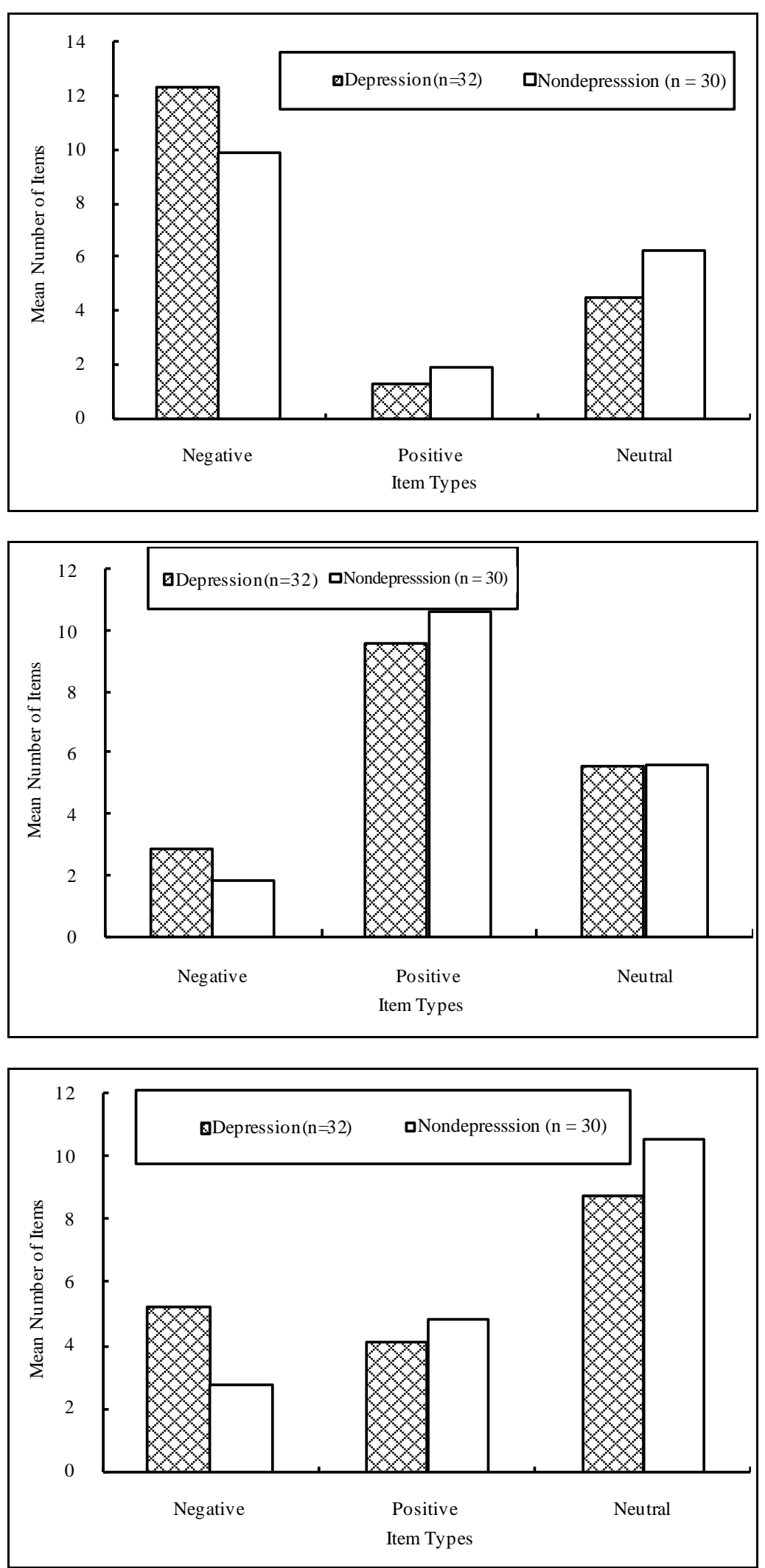

Figure 7. Analysis on priming processing of positive, negative and neutral items of participants. 


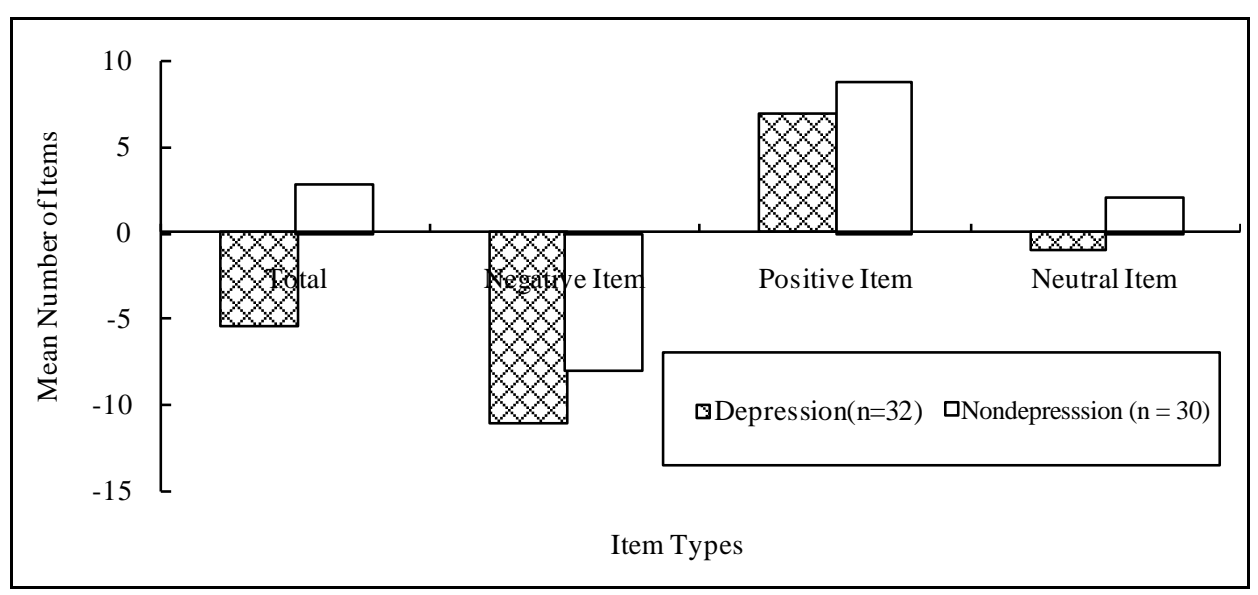

Figure 8. Analysis on priming bias of the participants.

and nondepression group, we found that both the depression and the nondepression group recalled more information consistent with the given condition. Furthermore, there was no significant difference in the total recalled volumes between positive and neutral conditions, but in the negative condition, the recalled volume of the depression group was more than that of the nondepression group. While under neutral condition, the participants in the depression group recalled more negative information than the nondepression group. These results were consistent with the findings of previous studies (Derry \& Kuiper, 1981; Dobson \& Shaw, 1987; Qian, Li, \& Zhang, 1998), suggesting that the recall of the depressed participants was influenced by the social situation and presents social negative schemata.

Further analysis on the processing bias under different conditions shows that the participants in the depression group recalled fewer positive items under positive conditions, more negative and neutral items under negative conditions, and more negative items and fewer positive and neutral items under neutral conditions, which indicates that the social cognitive schemata of the middle school students with depressive symptoms are related to the emotional states without a unstable structure. Many researchers tried to investigate emotional disorders from the aspect of information-processing bias, which mainly emphasizes on the perceiving and encoding process, the understanding process and the memory storing process. "The Accessibility Hypothesis" was postulated and proposed that the individuals in active (or passive) emotional states would prefer to recall active (or passive) material, because the thoughts related to or inducing active (or passive) emotional states could effectively reveal the other active (or passive) material in memory to make it easier to access this kind of material (Wang \& Fu, 2001; Teasdale \& Segal, 1995; Spangler \& Simons, 1997). In our study, when the meaning of the information was consistent with the emotional states of the participants, the information-processing bias was greatly elicited. These results in the present study provide a compelling support for this hypothesis.

\subsubsection{Recognition Characteristics of Middle School Students with Depressive Symptoms}

Experiment 2 found that for the original items, depressed participants recognized more negative than positive items, while depressed participants recognized more positive than negative items. For the newly-added items, depressed participants recognized more negative than neutral items, but there was no significant difference in volume of three types of item recognized by nondepressed participants. Furthermore, compared with the nondepressed participants, depressed participants had significantly more recognized volume of the original and newly-added negative items, but less of the original positive items. Lastly, depressed participants had bias towards negative original and newly-added items while nondepressed participants had bias towards positive original items and negative newly-added items. These results were similar to previous findings (Qian et al., 1998; Ingram et al., 1994) which reveals that the depressed had negative social schemata.

Volume of recognized items can be considered as an index of self schemata and is highly associated with emotional state (Qian et al., 1998). Current study found that individuals with depressive emotions recognized equal volume of positive and negative items at the level of word and phrase, but more negative than positive items at the level of sentence. This suggests that 1 ) negative social schema is relatively stable, and at the level of word and phrase, negative self schemata are closely related to emotional state; 2) compared with sentences, it is 
more difficult for words and phrases to activate negative self schemata since they provide less information.

In addition, there was significant difference in the recognition for the original and newly-added items in the middle school students with depressive symptoms. Since recognizing original and newly-added items requires different cognitive processing depths, our results reveal that processing depth determines the recognition level of depressed individuals.

\subsubsection{Priming Processing Characteristics of Middle School Students with Depressive Symptoms}

Experiment 3 found that positive, negative and neutral stimuli primed more negative items in depression group and more neutral items in nondepression group, which indicates that the middle school students with depressive symptoms may have negative priming process. Further analysis found that positive and negative items presented in advance could generate corresponding positive and negative priming effects. Meanwhile, after priming by negative items, depressed individuals generated more negative items, while the nondepressed generated more neutral items. Negative priming effect of neutral items was significantly greater in the depression group than in the nondepression group. But priming effect of positive items had no group difference.

By using formula of "number of positively primed item - number of negatively primed item", we found that the middle school students with depressive symptoms had significant negative priming bias in negative, neutral and total items, suggesting the negative priming bias of these students. This is consistent with the findings of studies on basic cognitive process.

Many researchers have tried to explain the underpinning mechanisms such priming bias. Philipchalk et al. (1995) proposed that once the schema of a certain concept is activated by a specific stimulus, the schema could affect the way of understanding internal or external environments. When individuals try to explain the ambiguous information, they usually incline to use newly-activated psychological schemata as reference. Moreover, Wyer \& Srull (1989) considered that the priming effect is induced by stimuli that can activate behavior-related concepts at the top of one's lexicon. Therefore, individuals may unintentionally use these concepts activated by priming to evaluate the stimuli. Zhong \& Gao (1995) found that the stimuli occurring in advance could positively or negatively affect subsequent social cognitive activities. Based on previous studies and the results of current study, we proposed that depressed individuals have both positive and negative schemata, but the activation threshold of negative schemata is relatively low. Thus negative schemata can be activated easily by negative or even neutral stimuli. To verify this point, further investigations are needed.

\section{Conclusion}

To summarize, by utilizing Tversky's experimental paradigm, this experiment explored the cognitive processes of school life events (positive, negative and neutral) of middle school students. The students can not only generate negative cognitive processing but also negative social cognitive processing. They have positive and negative social cognitive schemata with different activation thresholds. The threshold of negative social cognitive schemata is low but of positive schemata is high. Therefore, both positive and negative life events can activate corresponding social cognitive schemata, but low-intensity life events could activate negative ones that are usually more easily for its low threshold, and thereby cause negative emotions and behaviors.

\section{Acknowledgements}

The research reported in this article was supported by 12 middle schools in Chongqing Municipality and Sichuan Province. Here we particularly thank the seventh middle school in Chongqing Municipality, Ba County middle school in Chongqing Municipality, Changzheng middle school in Chongqing Municipality, Leshan Education Committee in Sichuan Province, Huayang middle school in Sichuan Province, and Nanchong middle school in Sichuan Province. And many thanks to the active participation of all the participants!

\section{References}

Abramson, L. Y., Metalsky, G. I., \& Alloy, L. B. (1989). Hopelessness Depression: A Theory Based Subtype of Depression. Psychological Review, 96, 358-372. http://dx.doi.org/10.1037/0033-295X.96.2.358

Bandura, A., \& Pastorelli, C. (1999). Self-Efficacy Pathways to Childhood Depression. Journal of Personality and Social Psychology, 76, 258-269. http://dx.doi.org/10.1037/0022-3514.76.2.258

Beck, A. T., Rush, A. J., Shaw, B. F., \& Emery, G. (1979). Cognitive Therapy of Depression (pp. 5-37). New York: Quilford 
Press.

Beck, A. T., Ward, C. H., Mendelson, M., Mock, J., \& Erbaugh, J. (1961). An Inventory for Measuring Depression. Archives of General Psychiatry, 4, 561-571. http://dx.doi.org/10.1001/archpsyc.1961.01710120031004

Chen, S. L. (2001). Theoretical Study of Social Cognition of Depression. Journal of Clinical Psychology Medicine, 11, 240-242.

Chen, S. L., \& Zheng, Q. Q. (1999). Psychological-Social Factors of Undergraduates with Depressive Emotion. Chinese Journal of Clinical Psychology, 7, 101-102.

Chen, S., \& Qian, Y. M. (1998). Task Expectation Change and Social Comparison Traits of Undergraduates with Depressive Trend. Journal of Clinical Mental Health, 12, 165-168.

Denny, E. R., \& Hunt, R. R. (1992). Affective Valence and Memory in Depression: Dissociation of Recall and Fragment Completion. Journal of Abnormal Psychology, 101, 575-580. http://dx.doi.org/10.1037/0021-843X.101.3.575

Derry, P. A., \& Kuiper, N. A. (1981). Schematic Processing and Self-Reference in Clinical Depression. Journal of Abnormal Psychology, 90, 286-297. http://dx.doi.org/10.1037/0021-843X.90.4.286

Dobson, K. S., \& Shaw, B. (1987). The Specificity and Stability of Self-Referential Encoding in Clinical Depression. Journal of Abnormal Psychology, 96, 34-40. http://dx.doi.org/10.1037/0021-843X.96.1.34

Dodge, K. A., \& Price, J. M. (1994). On the Relation between Social Information Processing and Socially Competent Behavior in Early School-Aged Children. Child Development, 65, 1385-1397. http://dx.doi.org/10.2307/1131505

Egan, S. K., Monson, T. C., \& Perry, D. G. (1998). Social-Cognitive Influences on Change Aggression Over Time. Developmental Psychology, 34, 996-1006. http://dx.doi.org/10.1037/0012-1649.34.5.996

Garber, J., Weiss, B., \& Shanley, N. (1993). Cognitions, Depressive Symptoms and Development in Adolescents. Journal of Abnormal Psychology, 102, 47-57. http://dx.doi.org/10.1037/0021-843X.102.1.47

Ingram, R. E., Partridge, S., Scott, W., \& Bernet, C. Z. (1994). Schema Specificity in Subclinical Syndrome Depression: Distinctions between Automatically versus Effortfully Encoded State and Trait Depressive Information. Cognitive Therapy \& Research, 18, 195-209. http://dx.doi.org/10.1007/BF02357775

Kessler, R. C. (1997). The Effects of Stressful Life Events on Depression. Annual Review Psychology, 48, 191-214. http://dx.doi.org/10.1146/annurev.psych.48.1.191

Philipchalk, R. P. (1995). Invitation to Social Psychology (pp. 127-128). Orlando, FL: Harcout Brace \& Company.

Qian, Y. M., Li, X., \& Zhang, G. J. (1998). Experimental Study on Depressive Self-Schema. Acta Psychologica Sinica, 30, 337-342.

Spangler, D. L., Simons, A. D., Monore, S. M., \& Thase, M. E. (1997). Comparison of Cognitive Models of Depression: Relationships between Cognitive Constructs and Cognitive Diathesis-Stress Match. Journal of Abnormal Psychology, 106, 395-408. http://dx.doi.org/10.1037/0021-843X.106.3.395

Teasdale, J. D., Segal, Z. V., \& Williams, J. M. G. (1995). How Does Cognitive Therapy Prevent Depressive Relapse and Why Should Attentional Control (Mindfulness) Training Help? Behavior Research \& Therapy, 33, 25-29. http://dx.doi.org/10.1016/0005-7967(94)E0011-7

Tversky, B., \& Marsh, E. J. (2000). Biased Retelling of Events Yield Biased Memories. Cognitive Psychology, 40, 1-38. http://dx.doi.org/10.1006/cogp.1999.0720

Wang, X. J., \& Fu, C. (2001). Information Process and Emotional Disorder-Western's New Attempt about Emotional Disorder. Psychology Trend, 9, 163-167.

Watkins, P. C., Mathews, A., Williamson, D. A., \& Fuller, R. D. (1992). Mood-Congruent Memory in Depression: Emotional Priming or Elaboration? Journal of Abnormal Psychology, 101, 581-586. http://dx.doi.org/10.1037/0021-843X.101.3.581

Wyer, R. S., \& Srull, T. K. (1989). Memory and Cognition in Social Context (pp. 1-66). Mahwah, NJ: Lawrence Erlbaum Associates.

Zhong,Y. P., \& Gao, D. G. (1995). Review of Wyer’s Social Cognitive Mode. Psychology Science, 18, 103-107. 


\section{Appendixes}

\section{Appendix A: Experimental Reading Material and Experimental Materials (Norm)}

The Roommate Story (S: Social; A: Annoying; N: Neutral)

You are a senior in a middle school. You've just moved into a new dormitory, and find yourself with two new roommates (Zhang Ran and Liu Xing). Each of you brought furnishings from home: Zhang Ran brought a desk lamp (N), Liu Xing brought chairs (N), and you have just purchased white curtains (N). Two hours later, the three of you start to get to know each other. Zhang Ran came from a key middle school (N), and Liu Xing was from a national famous middle school $(\mathrm{N})$.

On the first morning, Zhang Ran's alarm wakes you up (A). You get up, trip over a pile of Zhang Ran's books (which seem to be everywhere) (A), and stagger to the bathroom only to find it occupied by Liu Xing (A). Later, the three of you eat breakfast together, and start talking: Liu Xing has just come back from Dali in Yunnan province $(\mathrm{N})$, and describes a great sightseeing trip he took with his new friends (S). Zhang Ran, who has just returned from Beijing $(\mathrm{N})$, remarks on how he still keeps in close touch with his foreign friends $(\mathrm{S})$. Afterwards, Liu Xing leaves a pile of remains of food in the sink (A).

In the evening, the three of you decide to throw a party. Early on, Liu Xing eats a piece of bread (N) and chats with the classmates in other dormitories (S). Zhang Ran munches on lots of chips (N) and spills drinks all over your new curtains (A). As the party continues, Liu Xing is always in the center of a large group (S), and Zhang Ran keeps telling funny jokes (S). Later on, it turns out Liu Xing is a great dancer (S), but he releases dance music with your recorder (A).

The next day, the three of you go to classroom to have self-study. You can fairly concentrate your energy as Liu Xing sits across the table from you and talks with you loudly (A), while Zhang Ran (who is sitting next to you) constantly strikes on the table with his pen (A). Liu Xing talks interesting matters about stars and assesses the other classmates (A), and Zhang Ran leafs through his books one by one and makes loud noise (A). Later on, Zhang Ran returns the books borrowed from his classmates $(\mathrm{N})$, and Liu Xing takes out a film pictorial and enjoys with other classmates (S). Zhang Ran plays basketball with friends (S) as you leave the classroom for the dormitory, so Liu Xing reads the ads on the bulletin board $(\mathrm{N})$.

That afternoon, the three of you decide to participate the Literary Association organized by the school because Liu Xing knows several upperclassmen (S). Zhang Ran often goes there to retell the same boring stories (A), and his friends are always chatting and laughing with him (S). The dim lighting hurts Liu Xing's excessively shortsighted eyes (N), but that doesn't stop him from reading while you persuade him (A). Later, Zhang Ran buys snacks $(\mathrm{N})$ and shares them with the others (S), while Liu Xing discusses the development of the Literary Association (S).

The third day afternoon you try to study, but Liu Xing is talking with his parents on the phone so loudly that you give up quickly (A). Instead, you start to pick up Zhang Ran's unwashed lunch box (which seems to already be growing mold) (A), and pile up Liu Xing's unwashed clothes and books into a smelly heap on the desk and bed (A). Catching sight of Zhang Ran, you ask him if he has seen your leather jacket anywhere, and he replies that he borrowed it and he's not sure where he left it (A). A little while later, Liu Xing grabs his wallet (N) and Zhang Ran puts on his hat $(\mathrm{N})$, and they rush out the door. Zhang Ran hurries off for a basketball game with his friends (S), and Liu Xing for a football game (S).

The fourth day the teacher announces to have an assessment test. Although Zhang Ran throws himself into the strained review for the test $(\mathrm{N})$, he still plays basketball with his friends in his spare time (S). Liu Xing is writing a text of a speech $(\mathrm{N})$ and discusses with several classmates who will become the class leaders of your class (S).

The fifth day Liu Xing finishes the speech recording to run for the class leaders together with several classmates (S), but destroys your recorder (A). Zhang Ran uses up all your shampoo (A), and he explains to you that is for a date (S). Thus the first week ends in this way.

\section{Appendix B: Experimental Recalling Materials}

Instructions I: One of your new roommates, Zhang Ran, is pledging a fraternity and he needs a peer recommendation. The fraternity he has chosen has a reputation for partying and stresses sociability and athletic interest as its only criteria for joining. Zhang Ran is eager to become a member, so he asked you to write a letter stressing how much fun he can be. Please draft a letter of recommendation for Zhang Ran, being sure to cite specific 
experiences you had with him during your first week together. You will have 10 minutes to draft your letter!

Instructions II: You have decided you don't want to live with Liu Xing anymore, and the Office of Student Housing requires a detailed letter of complaint before considering any roommate reassignments. The Office of Student Housing emphasizes lack of consideration and the occurrence of inconveniences as its only criteria for moving. You are anxious to move, so you decide to write a letter emphasizing how difficult Liu Xing is to live with. Please draft a letter of complaint against Liu Xing, being sure to site specific examples form your first week together. You will have 10 minutes to draft your letter!

Instructions III: Please recall as much of the detail of Liu Xing's and Zhang Ran's activities or any other information about them as possible. You do not need to worry about the exact wording or order of what you recall, just recall as much about them as you can. You will have 10 minutes to do so!

\section{Appendix C: Experimental Recognition Materials}

Instructions: Dear friends! According to the materials that you have read, please answer the following 108 questions one by one. If the content of the question matches the reading material, please mark a " $\sqrt{ }$ " in the parentheses; if not, please mark a "×". You will have 15 minutes to do so!

1. Does Zhang Ran play basketball with his friends in his spare time? ( )

2. Does Liu Xing finish the speech recording to run for the class leaders together with several classmates? ( )

3. Does Liu Xing destroy the recorder of his classmate? ( )

4. Does Zhang Ran like retelling stories? ( )

5. Does Liu Xing like Chinese? ( )

6. Does Zhang Ran play volleyball? ( )

7. Does Zhang Ran break the cup of his classmate carelessly? ( )

8. Does Liu Xing assess the other classmates? ( )

9. Does Zhang Ran come from a key middle school? ( )

10. Does Zhang Ran play volleyball with his friends in his spare time? ( )

11. Does Zhang Ran throw himself into the strained basketball match? ( )

12. Does Liu Xing place his operating log on the table and bed disorderly? ( )

13. Does Zhang Ran play chess with the classmates in other dorms? ( )

14. Does Liu Xing discuss the contents of the classwide meeting with several classmates? ( )

15. Is Liu Xing always in the center of a large group? ( )

16. Does Liu Xing tour in Dali in Yunnan province during the summer vacation? ( )

17. Does Zhang Ran play basketball with his classmates? ( )

18. Does Zhang Ran like potato chips? ( )

19. Does Liu Xing take up his portable radio? ( )

20. Is Liu Xing a great singer? ( )

21. Does Zhang Ran play cards with his classmates? ( )

22. Is Liu Xing a great dancer? ( )

23. Does Liu Xing enjoy film pictorials with his classmates? ( )

24. Does Liu Xing talk with his parents on the phone loudly? ( )

25. Does Zhang Ran strike the table with his pen? ( )

26. Does Zhang Ran like English? ( )

27. Is Liu Xing excessively shortsighted? ( )

28. Does Zhang Ran have a date? ( )

29. Does Zhang Ran share snacks with the others? ( )

30. Does Liu Xing take up his wallet? ( )

31. Does Zhang Ran's alarm wake up his classmates? ( )

32. Does Zhang Ran eat pot-stewed food? ( )

33. Does Liu Xing like bread? ( )

34. Does Zhang Ran throw himself into the strained review for test? ( )

35. Does Liu Xing destroy the desk lump of his classmate? ( )

36. Doesn't Liu Xing stop from reading while his classmate persuades him? ( )

37. Doesn't Liu Xing know several upperclassmen? ( ) 
38. Does Zhang Ran like fried chicken's legs? ( )

39. Is Liu Xing from a national famous middle school? ( )

40. Is Zhang Ran proud of learning several Shanghai dialects? ( )

41. Does Zhang Ran make faces in class? ( )

42. Does Zhang Ran like performing opusculum? ( )

43. Does Liu Xing play football with his classmates? ( )

44. Does Zhang Ran do his homework and make loud noises at the same time? ( )

45. Do Zhang Ran's sport shoes seem to be everywhere in the dorm? ( )

46. Does Liu Xing discuss with several classmates who will become the class leaders? ( )

47. Does Liu Xing join the School's Psychological Association? ( )

48. Does Liu Xing like history? ( )

49. Does Liu Xing bring chairs? ( )

50. Does Liu Xing tour in Tibet during summer vacation? ( )

51. Do Liu Xing’s unwashed clothes and books pile on the desk and bed? ( )

52. Does Liu Xing see a film with his classmates? ( )

53. Does Liu Xing sponsor the bulletin board? ( )

54. Does Zhang Ran borrow his classmate's watch? ( )

55. Does Liu Xing talk loudly on the phone with his classmate? ( )

56. Does Zhang Ran put on his hat? ( )

57. Does Zhang Ran's cry wake up his classmates? ( )

58. Does Liu Xing bring a camera? ( )

59. Does Liu Xing become the leader of the basketball team? ( )

60. Does Zhang Ran buy a computer? ( )

61. Is Zhang Ran from a national famous school? ( )

62. Does Zhang Ran talk everything under the sun with the classmates in other dorms? ( )

63. Does Liu Xing learn English with his classmate's repeater? ( )

64. Does Zhang Ran make loud noises when turning pages? ( )

65. Does Zhang Ran chat and laugh with his classmates? ( )

66. Does Zhang Ran spill drinks all over the new curtains bought by his classmate? ( )

67. Is Zhang Ran's lunch box already growing mold? ( )

68. Does Zhang Ran buy pot-stewed food? ( )

69. Does Zhang Ran join the school's orchestra? ( )

70. Does Zhang Ran bring any fruits? ( )

71. Does Zhang Ran like telling funny stories? ( )

72. Does Liu Xing know several upperclassmen? ( )

73. Do Zhang Ran's books seem to be everywhere in the dorm? ( )

74. Does Zhang Ran play basketball? ( )

75. Does Liu Xing leave a pile of remains of food in the sink? ( )

76. Does Liu Xing write a text of speech? ( )

77. Does Liu Xing talk the sightseeing and his new friends in Dali in Yunnan Province? ( )

78. Does Liu Xing write a novel? ( )

79. Does Zhang Ran play shuttlecock with his classmate? ( )

80. Does Liu Xing occupy the toilet for a long time? ( )

81. Does Zhang Ran bring a desk lamp? ( )

82. Is Liu Xing from an ordinary school? ( )

83. Does Zhang Ran borrow his classmate's leather jacket? ( )

84. Does Liu Xing read the bulletin board? ( )

85. Does Liu Xing like noodles? ( )

86. Does Zhang Ran buy several bags of snacks? ( )

87. Does Liu Xing play table tennis with his classmates? ( )

88. Do Zhang Ran's unwashed clothes grow mold? ( )

89. Does Zhang Ran ever tour in Beijing? ( )

90. Does Liu Xing release dance music with his classmate's recorder? ( ) 
91. Does Liu Xing throw bread in the sink? ( )

92. Does Zhang Ran like discussing the national current events? ( )

93. Does Liu Xing often argue and fall out with his classmates? ( )

94. Does Liu Xing copy his classmate’s homework? ( )

95. Does Zhang Ran ever tour in Shanghai? ( )

96. Does Zhang Ran return the borrowed books? ( )

97. Does Liu Xing discuss the development of the Literary Association with the others? ( )

98. Does Zhang Ran return the borrowed money? ( )

99. Does Liu Xing set up the class basketball team with his classmates? ( )

100. Does Liu Xing insult his classmates? ( )

101. Does Zhang Ran use up his classmate’s shampoo? ( )

102. Does Liu Xing have normal sight? ( )

103. Does Zhang Ran like mathematics? ( )

104. Is Zhang Ran proud of having good communication with his foreign friends? ( )

105. Does Liu Xing talk the sightseeing and his new friends in Tibet? ( )

106. Does Liu Xing talk loudly with his next-table neighbor? ( )

107. Does Zhang Ran use up his classmate's tea? ( )

108. Does Liu Xing occupy his classmate's desk for a long time? ( )

\section{Appendix D: Experimental Priming Materials}

Instructions: Dear friends! There are 54 uncompleted sentences below. The first half of the sentence is the scene described in the reading materials you just read. Please write out the second half according to your understanding to make the sentence complete. You will have 20 minutes to do so!

1. Liu Xing releases dance music with his classmate's recorder, and he will

2. Liu Xing is always in the center of a large group, and he will

3.Zhang Ran likes potato chips, and he will

4. Zhang Ran likes English, and he will

5. Liu Xing talks loudly with the next-table neighbor, and he will

6. In the party,Liu Xing eats bread, and he will

7. Zhang Ran plays basketball with his classmates in his spare time, and he will

8. Zhang Ran buys several bags of snacks, and he will

9. Zhang Ran spills drinks all over the new curtains his classmate bought carelessly, and he will

10. Liu Xing occupies the toilet for a long time, and he will

11. Zhang Ran tours ever in Beijing, and he will

12. Liu Xing discusses the development of the Literary Association with the others, and he will

13. Zhang Ran uses up his classmate's shampoo, and he will

14. Zhang Ran's unwashed lunch box is already growing mould, and he will

15. Liu Xing brings chairs, and he will

16.Some classmates persuades Liu Xing not to read in the room with dim light, and he will

17. Zhang Ran makes loud noise when turning pages, and he will

18. Liu Xing plays football with his classmates, and he will

19. Zhang Ran shares snacks with the others, and he will

20. Liu Xing is a great dancer, and he will

21. Zhang Ran is from a key school, and he will

22. Zhang Ran talks everything with the classmates in other dorms, and he will

23. Liu Xing takes up his wallet,and he will

24. Liu Xing enjoys film pictorials together with his classmates, and he will

25. Zhang Ran returns the borrowed books, and he will

26. Zhang Ran is proud of having good communication with his foreign friends, and he will

27. Zhang Ran likes telling funny jokes, and he will

28. Zhang Ran puts on his hat, and he will

29. Zhang Ran likes retelling stories, and he will 
30.Liu Xing assesses the other classmates, and he will

31. Liu Xing likes Chinese, and he will

32. Liu Xing talks loudly with his parents on the phone, and he will

33. Liu Xing is from a national famous school, and he will

34. Liu Xing reads the bulletin board, and he will

35. Zhang Ran strikes the desk with his pen, and he will

36. Liu Xing discusses with several classmates who will be the class leaders, and he will

37. Zhang Ran throws himself into the strained review for test, and he will

38. Zhang Ran plays basketball, and he will

39. Liu Xing knows several supperclassmen, and he will

40. Zhang Ran's books seem to be everywhere in the dorm, and he will

41. Zhang Ran brings a desk lamp, and he will

42. Liu Xing finishes the speech recording to run for the class leaders together with several classmates, and he will

43. Zhang Ran chats and laughs with his classmates, and he will

44. Zhang Ran's alarm wakes up his classmates, and he will

45. Zhang Ran has a date, and he will

46. Liu Xing is excessively shortsighted, and he will

47. Liu Xing talks the sightseeing and his new friends in Dali in Yunnan province, and he will

48. Liu Xing writes a text of speech, and he will

49. Zhang Ran borrows his classmate's leather jacket, and he will

50. Liu Xing leaves a pile of remains of food in the sink, and he will

51. Liu Xing destroys his classmate's recorder, and he will

52. Liu Xing tours in Dali in Yunnan province during summer vacation, and he will

53. Liu Xing's unwashed clothes and books piles on the desk and bed, and he will

54. Zhang Ran plays basketball with his classmates, and he will 